\title{
Constituindo-se Professora que Ensinará Matemática nos Anos Iniciais: o que Revelam as Narrativas Quanto a Alfabetização Matemática?
}

\author{
Becoming a Teacher Who Will Teach Mathematics in the Early Years: What Narratives \\ Reveal About Mathematical Literacy?
}

\author{
Américo Junior Nunes da Silva
}

Universidade do Estado da Bahia, Departamento de Educação, Programa de Pós-Graduação Stricto Sensu em Educação, Cultura e Territórios Semiáridos. BA, Brasil.

E-mail: ajnunes@uneb.br

\begin{abstract}
Resumo
Este artigo é recorte de um doutoramento, resultado de uma pesquisa narrativa, e objetiva investigar o que revelam as narrativas de estudantes do curso de Pedagogia da Universidade Federal de São Carlos (UFSCar), construídas durante dois encontros da disciplina "Matemática: conteúdos e seu ensino", sobre a ludicidade, o ensinar matemática no ciclo de alfabetização e o constituir-se professora que ensinará matemática nos anos iniciais. Nesse percurso, escolhemos as narrativas enquanto método e fenômeno a ser estudado. Constituímos diários de formação, produzidos pelas cinco participantes e por mim, e as entrevistas narrativas realizadas, como textos de campo. O processo de análise realizado se deu por meio da análise narrativa. As narrativas produzidas revelaram algumas dificuldades conceituais sobre a matemática e o processo de alfabetização matemática. Ao longo dos encontros, percebemos que as diferentes estratégias formativas propostas contribuíram para repensar essas crenças e ressignificar essas marcas negativas e as dificuldades que apresentaram.
\end{abstract}

Palavras-chave: Alfabetização Matemática. Formação Inicial de Professores. Narrativas. Diários de Formação.

\begin{abstract}
This article is an excerpt from a PhD, the result of a narrative research, and aims to investigate what the narratives of students in the Pedagogy course at the Federal University of São Carlos (UFSCar) reveal, built during two meetings of the discipline "Mathematics: Contents and their teaching ", On playfulness, teaching mathematics in the literacy cycle and becoming a teacher who will teach mathematics in the early years. Along this path, we chose narratives as a method and phenomenon to be studied. We constituted the training diaries, produced by the 05 participants and mine, and the narrative interviews carried out, as field texts. The analysis process carried out took place through narrative analysis. The narratives produced revealed some conceptual difficulties about mathematics and the mathematical literacy process. Throughout the meetings, we realized that the different training strategies proposed contributed to rethink these beliefs and reframe these negative marks and the difficulties they presented.
\end{abstract}

Keywords: Mathematical Literacy. Initial Teacher Training. Narratives. Training Diaries.

\section{Introdução}

A aprendizagem da matemática, tendo em vista os resultados das últimas avaliações externas realizadas no Brasil, sinaliza um descompasso entre o que é ensinado nas escolas e as efetivas aprendizagens conceituais dessa ciência. Infelizmente, como apontam esses dados, muitos são os estudantes que concluem o percurso da Educação Básica sem as habilidades necessárias. Essa problemática, para além das salas de aula, nos faz pensar sobre os cursos de formação inicial e como esses professores que ensinam matemática estão sendo preparados.

No que tange aos professores que ensinarão matemática nos anos iniciais, foco deste artigo, muitos são os estudantes que chegam ao curso de formação inicial com dificuldades conceituais. Em suas pesquisas, por exemplo, Almeida (2009) e Trujillo (2009) evidenciam que muitos estudantes concluem o curso sem os conhecimentos matemáticos necessários para a prática docente. Situação preocupante para quem precisa promover espaços de matematizar cotidianamente em sua atividade profissional.

Os trabalhos de pesquisa evidenciados anteriormente, corroborando ao que apresenta Serrazina (1999), revelam que os conhecimentos desses profissionais, que ensinam matemática nos anos iniciais, resumem-se, muitas vezes, aqueles construídos no percurso escolar primário e secundário. Por esse motivo, mas não somente por ele, como não considerar as histórias de vida desses profissionais e sua passagem pelos cursos de licenciatura?

Os futuros professores possuem um entendimento sobre o que é ser professor e ensinar matemática, algo construído ao longo de sua trajetória de vida e escolar, como sinalizaram Nacarato, Mengali e Passos (2009). Esse conhecimento prévio impacta o processo de formação e precisa ser considerado pelos formadores de professores, uma vez que são eles que pensarão em ações para (re)significar as marcas que esse saber prévio representa para os alunos em formação (SILVA; 
PASSOS, 2016).

Nesse sentido, partindo do apresentado e das inquietações que nos movimenta, elegemos como perguntas de pesquisa: As narrativas de licenciandos do curso de Pedagogia da UFSCar, construídas durante a formação inicial ${ }^{1}$, revelam elementos sobre a ludicidade, o ensino de matemática e o processo de constituir-se professor que ensina matemática nos anos iniciais? Que elementos, das histórias de vida dos participantes, são mobilizados e apresentados em registros narrativos, em relação à ludicidade e ao constituir-se professor que ensina matemática? Investigar o que revelam as narrativas de licenciandos do curso de Pedagogia, construídas durante dois encontros da disciplina de "Matemática: conteúdos e seu ensino", sobre a ludicidade, o ensinar matemática no ciclo de alfabetização e o constituir-se professor que ensina matemática nos anos iniciais é o que definimos como objetivo geral deste estudo.

Antes de avançarmos para a próxima seção nos cabem dois destaques: o primeiro deles é que a escrita deste artigo, principalmente pela natureza do que é proposto, assumirá diferentes "vozes": na primeira pessoa do singular, quando me referir, sobretudo, aos meus posicionamentos, experiências e parte de minha história de vida; na primeira e terceira pessoas do plural quando trouxer discussões que pertencem e foram construídas a partir do contato com os autores que me ajudaram nas discussões, a professora da disciplina e os demais participantes da pesquisa.

O segundo, por sua vez, é que para a leitura de textos de pesquisa oriundos de pesquisas narrativas, como nos apresentou o Professor Guilherme Prado durante a disciplina "Diálogos entre perspectivas Sócio-Históricas e Narrativas", que participamos na Faculdade de Educação da Unicamp (Universidade Estadual de Campinas), "não há espaço para um leitor preguiçoso, e o texto vai ganhando forma à medida que as experiências acontecem. O vai e vem é normal".

Nessa direção, atendendo ao proposto e em busca de ampliar o olhar acerca do objetivado, realizamos uma investigação ${ }^{2}$ apresentamos alguns dos resultados neste texto. Na tentativa de ser mais bem entendido pelo leitor o organizamos em seções: i) inicialmente apresentaremos o percurso metodológico da pesquisa; ii) em seguida, após sinalizar os participantes, os textos de campo e como aconteceram as análises dos dados, apresentaremos os registros narrativos construídos, a partir dos diferentes textos de campo, durante dois encontros da disciplina "Matemática: conteúdos e seu ensino" do curso de Pedagogia pesquisado; iii) e por último, apresentaremos algumas considerações acerca do trabalho de pesquisa.

\section{O Caminhar Metodológico}

A pesquisa narrativa foi escolhida, tendo em vista o que foi objetivado e apresentado na seção anterior, enquanto método e fenômeno a ser estudado, por ter sido entendida, como sinalizam Clandinin e Connely (2000), enquanto uma das formas de compreender a experiência. Para mim, nesse momento, a melhor forma de compreender a experiência ${ }^{3}$.

Pela própria dinâmica da pesquisa narrativa, percebemos que não há um caminho metodológico único para seguir que funcione para todas as investigações. Como destacam Clandinin \& Connelly (2015, p.181), as circunstâncias em volta de cada pesquisa, as relações construídas, a vida do pesquisador e as questões investigativas, os diferentes tipos de textos de campo ${ }^{2}$ e a versão final dos textos de pesquisa "[...] significam que a pesquisa é frequentemente cheia de incertezas". Precisamos, no movimento próprio de nossa pesquisa, encontrar o que melhor nos ajudaria a ampliar o olhar acerca do puzzle .

Por isso, entendendo esse percurso como particular para esta investigação, apresentaremos os participantes que ajudaram a construir esse texto e o percurso adotado. Foram 25 estudantes que inicialmente concordaram em participar da pesquisa, sendo que desses cinco se mantiveram até o final do percurso de produção de dados. A redução se deu por motivos

1 Tomamos por formação inicial, portanto, como o primeiro momento que prepara o sujeito para ingressar na profissão. De acordo com as Diretrizes Nacionais para a Formação Inicial de Professores, (BRASIL, 2001), essa formação precisa ser entendida e vivenciada como espaço que ensine o futuro professor a aprender de modo contínuo e reflexivo (PIMENTA, 1996), e explica que é no momento inicial da formação que o estudante começa a verse como professor, permitindo-se construir sua identidade docente.

2 Esta investigação foi aprovada pelo Comitê de Ética por meio do parecer 1.697.334, número CAAE 53374116.0.0000.5504 e trata-se de uma pesquisa de doutoramento realizada entre os anos de 2015 e 2018, na Universidade Federal de São Carlos, sob a orientação da profa. Dra. Carmen Lúcia Brancaglion Passos (Silva, 2018).

3 A experiência, neste momento, concordando com o que nos apresenta Bondía (2002, p. 21), “[ ...] é o que nos passa, o que nos aconteceu, o que nos toca. Não o que se passa, não o que acontece, ou o que toca. A cada dia se passam muitas coisas, porém, ao mesmo tempo, quase nada nos acontece". Infelizmente, nessa direção, como sinaliza Benjamin (1996), entendemos que a experiência está cada vez mais rara. Vivemos uma pobreza de experiência. Bondía, atualmente, tem preferido usar outra palavra em substituição ao termo "experiência". Segundo o autor, a palavra foi apropriada pelo mercado. Por isso ele tem falado em "exercício". No entanto, pensando o termo diferentemente do que tem concebido a lógica do mercado, decidimos mantê-lo neste artigo, seguindo o texto usado para essa fundamentação.]

4 Textos de campo, como nos apresentam Clandinin e Connelly (2015), são aqueles criados, não são encontrados e nem descobertos pelos participantes e pesquisadores. Eles objetivam representar aspectos da experiência de campo. "Os textos de campo auxiliam o pesquisador a mover-se retrospectivamente e prospectivamente em um completo envolvimento com os participantes e também distanciamento deles” (Clandinin \& Connelly, 2015, p.119). 5 Entendemos, nesse momento, partindo do que destaca Clandinin e Connelly (2015), uma aproximação teórico-metodológica, em relação ao uso do termo puzzle e o problema de pesquisa. De acordo com Clandinin (2013), é importante tecer justificativas relacionadas ao puzzle por inúmeras e diferentes razões: i) para compreender nossa posição em relação à pesquisa; ii) sem deixar claro os motivos que nos levaram a pesquisar tal temática, podemos iniciar um processo no qual não estabelecemos nenhuma relação; iii) precisamos compreender quem somos para, a partir daí, compreender as experiências de nossos participantes. 
diferentes. Explicarei a seguir.

Os participantes precisariam, para seguir na pesquisa, matricular-se na disciplina de "Matemática: conteúdos e seu ensino" e alimentar cotidianamente o diário de formação. Nem todos atenderam a esse critério. Outro motivo das desistências decorre do volume de atividades acadêmicas que os estudantes tinham nos semestres, o que, segundo eles, impossibilitava o registro das reflexões sobre as experiências no diário de formação.

Nesse sentido, portanto, fomos seis participantes: as cinco estudantes que aceitaram participar voluntariamente da pesquisa assinando o Termo de Consentimento Livre e Esclarecido (TCLE) e eu. Todas as questões éticas foram respeitadas. Todos participaram durante os percursos de construção dos textos de campo, que foram:

i) Participei, enquanto estagiário do Programa de Estágio Supervisionado de Capacitação Docente - $\mathrm{PESCD}^{6}$, acompanhando a disciplina e as estudantes. As minhas participações na disciplina, inclusive ministrando aulas, possibilitaram a construção de registros em meu diário de formação, muitos deles oriundos de minhas observações. Esse diário, portanto, constitui-se como o primeiro texto de campo construído;

ii) As estudantes, que aceitaram participar da pesquisa, construíram os seus diários de formação, com os registros narrativos oriundos de suas participações ao longo da disciplina. Nesses diários, elas registravam livremente as impressões, angústias, medos e alegrias do contato com as discussões, leituras dos textos propostos e demais questões relacionadas;

iii) Por último, para as participantes que se mantiveram até o fim, realizamos uma entrevista narrativa, seguindo o que apresenta Weller \& Zardo (2013) a esse respeito.

Temos na figura do diário, como nos apresentou Clandinin e Connelly (2015, p. 145), um “[...] meio poderoso para que as pessoas possam dar relatos de suas experiências”. Os diários talvez, e muitas vezes, assumem “(...) uma qualidade questionadora intimamente reflexiva, talvez menos como uma forma de relato de experiência, como observado por Sarton, e mais como uma forma de problematizar a experiência" (Clandinin \& Connelly, 2015, p.146).

A relevância das entrevistas narrativas na pesquisa qualitativa, como nos apresenta Weller e Zardo (2013, p.133), “[...] importa na contribuição que este instrumento fornece para a compreensão das estruturas processuais dos cursos de vida ou trajetórias dos sujeitos pesquisados" como destaca Apple (2005), fundamentando-se em Schutze (2011). Ainda segundo os referidos autores, "[...] o ato de rememorar e a narração da experiência vivenciada de forma sequencial permitem acessar as perspectivas particulares de sujeitos de forma natural" (Weller \& Zardo, 2013, p.133).

Nossa tarefa enquanto pesquisadores narrativos, como nos orientam Clandinin e Connelly (2015), não é, quando em contato com os textos de campo produzidos pelos diários, das participantes e o meu, bem como das transcrições das entrevistas narrativas, criar generalizações e dizer que pessoas, lugares e coisas são destas ou daquelas maneiras, mas que elas têm uma história narrativa e que estão avançando. Desejamos ampliar o olhar em relação ao puzzle de pesquisa.

Narrar a própria história, como destaca Caporale (2016, p.54), fundamentando-se em Finger \& Nóvoa (2010), “[...] desencadeia processos de reflexão e (re)significação dos sujeitos, compondo, portanto, de espaços de investigação e de formação". Partindo do que nos apresenta, compreendemos que é essa mesma reflexão que nos guia no processo de análise e interpretação dos textos de campo e escrita do texto de pesquisa, pois se trata de "[...] um processo coletivo de mútua explicação em que a vivência do investigador se imbrica na do investigado" (Cunha, 2007), sem perder de vista os conceitos que lhes são inerentes: a experiência, a temporalidade, a reflexividade, as interações e os contextos em que as histórias estão inseridas.

A análise dos textos de campo, portanto, não se limitam a dizer como as experiências ocorreram, ela vai muito além, principalmente quando pensamos e expressamos como pesquisador e participantes “[...] vivem, contam e interpretam suas histórias e criam novas histórias a serem vividas" (Mello, 2004 apud Caporale, 2016, p.80). Durante esse processo de composição de significados é preciso fazer escolhas e refletir profunda e continuamente sobre as histórias de vida dos participantes. Trata-se de um trabalho artesanal e único.

Nessa direção, no intuito de compor o texto de pesquisa, foi preciso interagir com os textos de campo. Procuramos, como fez Caporale (2016, p.80), “[...] ter um olhar em todas as direções, retrospectiva e prospectivamente, procurando perceber cada sujeito, seus sentimentos, suas indignações e indícios de sua construção identitária, entre outras possibilidades".

Procuramos, ainda referenciando o percurso construído por Caporale (2016, p.81), “[...] conhecer e compreender introspectiva e extrospectivamente os contextos de vida e de formação nos quais ocorreram as experiências de vida e situálos num lugar". Não perdendo de vista o captar as múltiplas vozes, as explícitas e as implícitas, contidas nas histórias contadas por mim, pesquisador e participante desta pesquisa; e recontar essas histórias a partir de intensas reflexões e interpretações das experiências.

\section{Matemática: Conteúdos e seu Ensino}

Essa seção, portanto, tem como objetivo apresentar a experiência e a análise construída a partir do contato que tivemos com os diferentes textos de campo produzidos, por mim e pelas demais participantes, ao longo das vivências propiciadas por dois encontros da disciplina de "Matemática:

6 A Resolução número 315/97-CEPE, de 03 de outubro de 1997, dispõe sobre a instituição do Programa de Estágio Supervisionado de Capacitação Docente- PESCD. Segundo o referido documento, o programa é destinado a aprimorar a formação de discentes de Pós-Graduação, oferecendo-lhes adequada preparação pedagógica, através de estágio supervisionado em atividades didáticas de graduação. 
conteúdos e seu ensino".

As cinco participantes, respeitando as questões éticas da pesquisa, escolheram serem chamadas por Hilda, Maria, Gabriela, Emily e Elisa. Pelo volume de reflexões construídas e tendo em vista o limitado espaço disponibilizado, decidimos focar, para este texto de pesquisa, em dois encontros.

Pela natureza da pesquisa narrativa realizada, optei neste texto de pesquisa, não fazer um capítulo específico para apresentar a fundamentação teórica, esta será feita articuladamente às nossas narrativas das experiências com os dois encontros da disciplina e nas análises realizadas. Vale destacar que os diários, meu e das participantes e as entrevistas narrativas foram elementos que nos permitiram constituir o seguinte texto narrativo de pesquisa.

\subsection{Contando um pouco sobre o primeiro encontro a partir do intercruzar dos textos de campo produzidos}

Por analisar o Projeto Pedagógico (São Carlos, 2012), antes do início da disciplina e conhecer a estrutura curricular do curso, percebemos as dificuldades com as questões referentes à alfabetização e ao letramento matemático. Tendo em vista a percepção de que a discussão de alfabetização e letramento matemático não tinha sido proposta em outro momento da formação inicial, como nos evidenciaram também as narrativas iniciais escritas pelas participantes em seus diários, decidimos por discuti-la neste encontro.

Algo que considero importante a ser destacado é que as discussões realizadas em sala de aula vão, muitas vezes, além do pensado por nós durante o planejamento. As discussões em sala vão seguindo diferentes caminhos, e para isso, levamos em consideração as diversas experiências das estudantes que participam da disciplina. Os questionamentos, dúvidas e considerações a respeito dos textos, das vivências propiciadas e das discussões realizadas em sala de aula nos direcionam para a construção da aula.

Antes de apresentar os registros presentes nos diários das participantes para esse encontro, é interessante confidenciar algo que tem visitado meus pensamentos. Não tive como não revisitar o que elas escreveram, mais uma vez, e refletir sobre as nossas responsabilidades enquanto professores da disciplina. Bateu aquele medo de falhar enquanto formador e uma preocupação com o perfil de educador matemático perseguido por nós.

Comecei a pensar sobre as outras vezes em que estive na posição de formador, no curso de Pedagogia, e elencar as experiências que foram vividas e o quanto elas repercutiram, pelo menos pela minha ótica, na formação dos futuros professores. Como não havia trabalhado anteriormente com narrativas escritas em diários, mesmo ouvindo as inquietudes dos estudantes no início de cada disciplina, algo que era comum para mim, parecia que agora, por estar escrito, as responsabilidades eram maiores. Estava, mesmo sem ter sido, me sentindo cobrado quanto ao trabalho que desenvolveríamos.
Como havíamos combinado, a professora e eu, demos ênfase neste encontro às questões voltadas à alfabetização matemática e decidimos por pontuar, desde o princípio, em consonância aos cadernos do Pacto Nacional da Idade Certa- PNAIC e com as demais leituras realizadas, que a "Alfabetização matemática é entendida [por nós nesse momento] como um instrumento para a leitura do mundo, uma perspectiva que supera a simples decodificação dos números e a resolução das quatro operações básicas" (Brasil, 2014, p.5).

Outra preocupação nossa era com a desmistificação da ideia de que para aprender matemática, o sujeito precisa estar alfabetizado. Como destaca Moretti e Souza (2015, p.16), essas situações ainda são facilmente constatadas nas práticas de escolarização das crianças nas escolas brasileiras. Somente rompendo com essa crença se torna "[...] possível pensarmos em processos de organização do ensino que, ao tempo que considerem a especificidade da infância, favoreçam e potencializem diferentes aprendizagens".

Sentia-me confortável com essas discussões, principalmente, pelas minhas vivências enquanto coordenadoradjunto do Pro-Letramento e do PNAIC na Bahia, enquanto formador do PNAIC no estado de São Paulo e como professor do curso de Pedagogia da Universidade do Estado da Bahia. Revisitar algumas leituras que foram feitas naquela época foi importante por me permitir (re)pensar algumas coisas que, naquele momento, pelas leituras e experiências de vida e profissional tidas, eram percebidas de modo diverso do atual.

Decidimos por problematizar com as estudantes: “[...] que conceitos e habilidades matemáticas são necessários para que a criança possa ser considerada alfabetizada dentro dessa perspectiva?" (Brasil, 2014, p.9). Usamos as leituras feitas para nortear essa discussão e para fundamentar essa seção.

Nas discussões que foram geradas era inevitável perceber o quanto as estudantes entendiam lúdico como parte importante do processo de construção dos conhecimentos. Elas pontuavam, volta e meia, a relação que a criança estabelece com o brincar e outras práticas sociais. Já identificávamos aqui, uma aproximação dos aspectos lúdicos como parte do universo da criança; além disso, muitas das estudantes presentes expressavam a ideia de que, por meio da ludicidade se consegue aproximar a criança do objeto matemático com mais facilidade (Moretti \& Souza, 2015).

Essa percepção da importância da ludicidade pode ter emergido com tanta força em nosso encontro, sobretudo, pelo fato de, nas leituras feitas, todos os autores, Moretti e Souza (2015), Moura (1996) e Vianna e Rolkouski (2014), enfatizarem a importância dos elementos lúdicos para a aprendizagem. Algo interessante das leituras são as diferentes abordagens apresentadas e as ressignificações que foram feitas pelas estudantes. Em linhas gerais, parece-nos que ficou claro que alguns recursos com potencial lúdico, como o jogo, por exemplo, são fundamentais para a criança conhecer, atuar e se apropriar do mundo que a rodeia (Moura, 1996).

Tentamos evidenciar, nesse momento, que o nosso foco 
precisava ser no fazer matemática. Os diferentes recursos com potencial lúdico, como os jogos e as brincadeiras, por exemplo, precisavam ser vistos como caminhos para essa aproximação (Muniz, 2016). As crianças, corroborando com o que destaca Moretti \& Souza (2015), se apropriam de conceitos matemáticos no fazer matemática. É preciso, como evidencia Moura (1996), entender que o conhecimento matemático é construído pela criança no "ato de fazer" por si mesma e na interpretação com os outros.

Em consonância com algumas ideias de alfabetização matemática apresentadas pelas estudantes na narrativa inicial, que nos serviu de base para entender algumas concepções trazidas para a disciplina, decidimos pontuar o que apresenta o material do PNAIC a respeito: “[...] ser alfabetizado é muito mais do que dominar apenas os rudimentos da leitura e escrita, mesmo sendo capaz de ler e escrever todas as palavras" (Brasil, 2014, p. 10). Ainda segundo o caderno do PNAIC, trazido para discussão no momento da aula, “(...) a pessoa alfabetizada é capaz de ler e escrever em diferentes situações sociais, de tal forma que isso the permita inserir-se e participar ativamente de um mundo letrado, enfrentando os desafios e demandas sociais" (Brasil, 2014, p.10).

A esse professor alfabetizador, como discutimos naquele momento, é importante permitir o diálogo entre a matemática e as outras áreas do conhecimento. "Entender a Alfabetização matemática na perspectiva do letramento impõe o constante diálogo com outras áreas do conhecimento e, principalmente, com as práticas sociais” (Brasil, 2014, p.15). Para isso, portanto, é importante que esse professor alfabetizador, como destaca Fonseca (2014, p.29), desenvolva “[...] uma ação pedagógica que ajude as crianças a compreenderem os modos como essa sociedade organiza, descreve, aprecia e analisa o mundo e as experiências que nele vive".

Nessa direção, levando em consideração o que nos apresentaram os autores anteriormente referenciados, por exemplo, lembramo-nos de uma fala de Hilda, apresentada durante a entrevista, que destaca, de certo modo, a importância que o processo de alfabetização tem para a construção do conhecimento matemático.

Olha, eu posso estar falando uma besteira, mas eu acho que a dificuldade não está na matemática. A dificuldade está na interpretação. Pelo menos para nós, dos últimos anos dos anos iniciais. Nossa dificuldade não tá nos cálculos, nos algoritmos, está na interpretação, está no entendimento, na informação que você precisa dar depois daquilo. Eu ainda acho que o problema não tá na matemática, mas no como ela está sendo proposta, na capacidade de entendimento desse aluno. Então vai envolver leitura, interpretação de texto. Eu não acho que é só a matemática a dificuldade. Eu acho que é o todo, o contexto, sabe? Eu acho que é você entender o contexto e saber que informação aquilo pede. Não acho que é só o dois mais dois. Não acredito nisso (Silêncio) [Hilda, informação verbal, 2018].
Se nos debruçarmos sobre essa fala, de certo modo, entenderemos que existe uma problemática: Muitas crianças, infelizmente, saem do ciclo de alfabetização sem conseguirem ler fluentemente e, consequentemente, interpretar e resolver problemas matemáticos. Elisa, em sua entrevista, manifestou a mesma preocupação durante a realização de estágio.

[...] Algumas crianças não sabiam ainda ler no $3^{\circ}$ ano, então isso dificultava um pouco. De qualquer forma ela tinha que dar conta do conteúdo. De certa forma a gente vê a bola de neve se formando aí. A criança não sabe ler e tem que dar conta do livro de matemática, mas ela não sabe ler o enunciado, então dificulta [Elisa, informação verbal, 2018].

Durante o encontro, e isso é interessante apontar, às vezes eu observava que algumas estudantes vagavam em pensamentos. Vendo alguns olhares fixos e perdidos pensava curioso: "será que elas estão entendendo a discussão que estamos fazendo?" "O que será que se passa em suas cabecinhas?".

Nesse sentido, munido da curiosidade que me moveu nesse primeiro momento, fui buscar no segundo dia de escrita narrativa feita em seus diários, o que registraram e se seus escritos davam pistas que respondessem às minhas inquietudes. Para minha surpresa me deparei com registros do tipo: "No decorrer da aula, enquanto a professora falava sobre o ensino de matemática, eu pensava: queria que meus professores tivessem sido assim". E então percebi que elas, durante a aula, relacionavam o encontro com a formação que tiveram em outros momentos da vida escolar, ao tempo que pensavam em sua futura prática docente.

Inevitável que elas, ao fazerem essa comparação com as professoras que tiveram em outros momentos da vida, (re)significavam a percepção que tinham sobre o que é ser um professor que ensina matemática. Elas comparavam as práticas das antigas professoras de matemática com as práticas que apresentávamos durante a disciplina. Nesse momento, começavam, acredito, a (re)pensar a sua (futura) prática e a construir um repertório metodológico, além, é claro, de desconstruir medos e equívocos quanto às questões matemáticas.

Vianna \& Rolkouski (2014, p.19) destacam que "[...] quando pensamos no ensino de matemática que tivemos, uma série de imagens nos vem à mente". Segundo os autores, essas imagens passam desde a colagem de bolinhas de papel em numerais com rostinhos, incontáveis continhas de mais e de menos até as competições de tabuada e de intermináveis expressões numéricas. Nesse caso, muitas vezes, quando isso é uma lembrança marcante, provavelmente tivemos uma matemática escolar que se restringia aos "usos" dos números e às quatro operações elementares. Algumas estudantes, como Maria, por exemplo, colaram em seu diário tarefas realizadas durante seu processo de alfabetização, guardadas desde então. Vejamos: 
Figura 1 - Atividade realizada por Maria

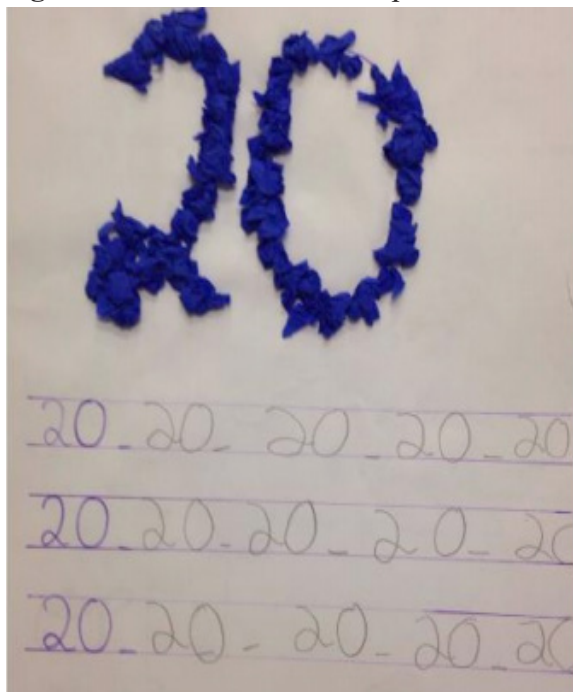

Fonte: Diário reflexivo da estudante Maria

Ainda provocados por Vianna e Rolkouski (2014), percebemos que, embora muitas décadas tenham se passado, algumas dessas práticas sobrevivem nas escolas. Além disso, como evidenciou a professora da disciplina, e nesse caso trago os mesmos autores anteriormente evidenciados para respaldar nossas inquietudes e provocações feitas nas aulas, muitas vezes introduzimos uma forma de organização dos cálculos feitos pelas crianças que são totalmente desnecessárias. Como sinalizou a professora durante a aula, ao impormos modelos de organização, desconsideramos as formas de pensar e registrar de nossos alunos.

Concordamos com Vianna e Rolkouski (2014) quando evidenciam que as diferentes formas de pensar e registrar das crianças devem ser incentivadas. Precisamos possibilitar o diálogo das crianças sobre suas próprias maneiras de pensar, evitando, dessa forma, que entendam que não devem pensar e sim adequar-se ao modelo requerido pela professora.

Os estudantes percebiam e internalizavam, como elemento importante para a sua futura prática, como registraram em seus diários, a importância de "[...] levantar com os alunos diversas formas de soluções de um problema, deixar que eles façam e expliquem suas ações e os porquês de terem realizado cada operação daquela forma", concordando ao que apresentaram Silva, Nascimento e Muniz (2017). Nesse sentido, como trouxe Moura (1996, p. 17) em seu texto, “[...] assumir a avaliação nesta perspectiva é considerar o 'erro' ou 'acerto' sinal de aprendizagem que deverá nortear as próximas ações”. Outra coisa que podemos inferir a partir da leitura feita em sala e das elaborações feitas pelas estudantes em seus diários é a percepção de que as produções dos alunos não são definitivas, pelo contrário, elas se modificam e avançam enquanto ocorre o processo de aprendizagem.

Muitas participantes, nas entrevistas, destacam justamente isso que apresentamos anteriormente. Vejamos alguns excertos que somam ao que os demais estudantes registraram em seus diários.
Emily: Ah, eu lembro que sim. Por exemplo: as estratégias de resolução... os probleminhas. Eu lembro que teve uma aula bem interessante que a gente ficou lá um tempão para resolver um problema (agora eu não lembro exatamente o que era). Mas assim... A Carmen tentou nos ensinar que existem várias formas de se resolver um problema e que a gente não precisa seguir um padrão ou uma fórmula certinha. Isso é diferente. A forma que eu aprendi, e não estou falando de muito tempo atrás, é diferente da visão que a matemática traz agora: várias resoluções de um único probleminha.

Elisa: [...] [A proposta da disciplina] era apresentar formas diferentes, como inovar, apresentar outras metodologias para dar um conteúdo. Então sim, eu acho que foi ótimo. Acho que foi pouco inclusive. [...]

Maria: Hoje eu acho que sim. Hoje eu entendo que o que ela estava mostrando não é que você não sabe, mas é que existem outras formas de ensinar e outras formas de fazer e que o resultado vai ser o mesmo. Mas que para ensinar a alguém você precisa entender a estrutura de cada um, porque cada um é cada um e você não vai conseguir explicar a todos de uma vez. Hoje eu entendo isso. Hoje eu estou mais confortável com isso. $[\ldots]$

Em relação aos registros feitos quanto às aprendizagens oriundas de nosso encontro, alguns conceitos elementares foram percebidos com surpresa por alguns estudantes. Vejamos o que um deles sinaliza em seu diário: "Eu não sabia o que a professora falou: 'o número é a representação gráfica de uma quantidade de itens'. Isso é o estopim de diversas oportunidades de serem exploradas".

Vale ressaltar, que discutimos durante o encontro, consoante ao que apresenta Fonseca (2014), que é preciso que os alfabetizadores compreendam os conceitos matemáticos envolvidos em todo o processo de alfabetização, para permitir a exploração das situações propostas. "É no confronto entre seus conhecimentos empíricos e os elementos teóricos característicos dos conceitos que as crianças operam processos de abstrações reflexivas" (Moretti \& Souza, 2015, p.11).

Em relação às leituras que foram realizadas para esse encontro, Emily destaca que “[...] os textos que lemos até agora estão ajudando a entender o significado do próprio trabalho da matemática com as crianças". Como forma de sintetizar o encontro ela resolve desenhar algo.

Figura 2- Desenho construído por Emily em seu diário

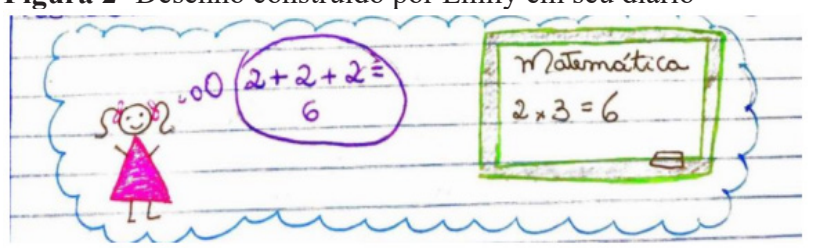

Fonte: Diário reflexivo da estudante Emily

Temos, no desenho construído por Emily, em seu diário, uma forma de representar o que foi significado do encontro, o que acreditamos que para ela tenha sido importante. Na figura, temos um quadro onde uma expressão numérica é apresentada e, pensamos, deve ter sido construída pela professora; mas, mesmo não sendo, algo que é comum, uma vez que os alunos também vão ao quadro, percebemos que a aluna representada no desenho tem um pensamento diferente para resolver a 
expressão.

Com esse desenho, acreditamos que Emily queria nos apontar a importância que há no valorizar as diferentes formas de matematizar das crianças. Elas, muitas vezes, apresentam caminhos diferentes para resolver expressões e outros problemas apresentados em sala. Para essa construção, utilizam suas vivências cotidianas, afinal, elas fazem matemáticas diariamente. Especificamente sobre essa imagem, observa-se que Emily representa o número 6 de duas maneiras diferentes.

Hilda, ao relatar sobre o ocorrido no $2^{\circ}$ encontro, destaca que voltar à universidade faz parte de um sonho de evoluir na carreira acadêmica e tornar a sua prática ainda mais especializada e de qualidade. No entanto, nos revela que disciplinas como essa e discussões como a ocorrida nesse encontro a amedrontam um pouco: "[...] morro de medo de descobrir que ensino algo errado aos meus alunos ou que determinadas práticas são incorretas".

Percebemos no posicionamento de Hilda uma abertura às aprendizagens propiciadas pelo espaço da formação inicial. Ela, ao que parece, reconhece a formação como um continuum e está aberta ao que o curso de formação propiciará. Como professora experiente, com nove anos de prática docente e coordenação na escola em que trabalha, apresenta-se apreensiva por ver que "[...] a minha responsabilidade com meus alunos é muito maior".

Sabíamos, a professora e eu, que não conseguiríamos dar conta de todos os conteúdos matemáticos e das questões metodológicas no pouco tempo que a disciplina nos propiciava; então, decidimos por transitar pelas diferentes unidades temáticas e propiciar uma reflexão em todas elas pelas estudantes. Tínhamos em mente que deveríamos apresentar uma postura do ser educador matemático, responsável, sobretudo, pela formação matemática dos estudantes e respeitando as diferentes formas de matematizar. Ficamos felizes com o encontro, principalmente por percebermos que as discussões geradas foram por demais produtivas e atingiam o que objetivávamos.

No entanto, mesmo com o fim do encontro, decidimos avaliar o que tinha acontecido ao longo da aula: por que a aula tomou esses rumos de discussão? Às vezes, as aulas fogem um pouco do "roteiro" que construímos. Mas isso não é necessariamente algo ruim, pelo contrário, é nesse momento que percebemos como a sala de aula é um espaço dinâmico, vivo e cheio de surpresas. Tudo isso é possível, claro, por conta dos sujeitos e das suas particularidades e singularidades.

Nesse espaço de sala de aula, cabe a participação de um professor igualmente dinâmico. Só assim, penso, conseguiremos assegurar que as particularidades, singularidades e subjetividades dos sujeitos sejam consideradas. Acho que as discussões que construímos durante a aula sobre o alfabetizador matemático contempla essa característica. Consideramos isso importante não somente nesse espaço de formação inicial, mas queremos que essa seja uma característica desse futuro professor e base de sua identidade docente.

Se me permitem, vou apresentar um exemplo dessa questão. Quando estava pensando em um roteiro para a aula, eu havia pensado em começar discorrendo sobre os termos alfabetização matemática, letramento matemático e numeramento, a partir do que Moretti \& Souza (2015) apresentam em seu livro. Mas isso não pareceu importante e nem foi destacado pelas estudantes no momento da discussão.

Outra coisa que fiquei pensando foi: como o estágio que elas fizeram na alfabetização poderia ter sido diferente, se anteriormente tivessem tido contato com essas discussões? Por que tudo isso não foi propiciado a elas a tempo da vivência desse estágio? Que professor o curso espera formar?

\subsection{Contando um pouco sobre o segundo encontro a partir do intercruzar os textos de campo produzidos}

Algumas falas apresentadas nas narrativas das estudantes voltam a me fazer pensar o processo de formação. Agora, por exemplo, percebo com mais naturalidade o quanto todo esse processo formativo está sendo importante para mim. Estar em uma perspectiva de pesquisa, como a narrativa, que valoriza o sujeito e a experiência nos coloca em outro lugar, diferentemente do que acontece em outras perspectivas.

Algumas questões postas por Clandinin e Connelly (2015), como a importância do pensar narrativamente, começam a ser naturalizadas. No momento que considero o sujeito, a experiência, o tempo e o lugar, eu circunscrevo a experiência e começo a perceber que desse ambiente construirei uma verdade, a verdade como é para mim, partindo da minha história de vida e formação e das experiências até esse momento.

Espero que as leituras indicadas para o último encontro tenham provocado as estudantes. Vou apresentar uma narrativa, presente em Teles (2014, p.38), que me fez pensar sobre o processo de formação inicial. Veja o que essa criança nos revela:

Era uma vez um menino... quando ele chegava em casa tinha que fazer a comida dos irmãos e tomar conta dos menores. Quando chegava na escola não sabia as tarefas e os colegas mangavam dele, aí ele ficava brabo e batia neles, batia mesmo... mas o que eu queria mesmo era aprender... e ser feliz.

O que essa narrativa nos provoca a pensar? Tendo contato com as narrativas das estudantes e conhecendo, agora, parte de suas histórias de vida, vejo que assim como para a criança do relato acima, algumas estudantes, como Elisa e Hilda, trabalham e, muitas vezes, precisam ir cansadas, sem banho e sem jantar para a aula. Normalmente, isso passaria despercebido, uma vez que comumente não se abre espaço para que as diferentes realidades sejam postas em sala de aula.

Acredito que as estudantes, futuras professoras, precisam considerar as diferentes realidades de seus futuros alunos ou, quando em estágio, dos alunos que fazem parte da sala em que 
estejam desenvolvendo as suas atividades. Essas diferentes realidades trazem implicações para o processo de ensino e aprendizagem dos alunos. O que se espera da escola/espaço de formação inicial? De que forma posso organizar meu trabalho pedagógico para assegurar que essas expectativas sejam atendidas?

Mas seria fácil entender isso como importante e considerá-lo/incorporá-lo em uma futura prática? Muitas vezes nós, formadores de professores, não consideramos e desconhecemos essas diferentes e singulares realidades. Parece que quando dizemos que é importante considerar as diferentes realidades, e não o fazemos com os nossos alunos, criamos uma distância que separa o discurso da prática, que pode, muitas vezes, ser mantida pelas estudantes.

Algumas estudantes disseram em suas narrativas iniciais que o que viveram enquanto alunas da Educação Básica não será determinante para suas futuras práticas. Penso: $\mathrm{O}$ espaço de formação inicial tem ajudado nessa ressignificação? E quando o que não deve ser seguido como exemplo para a prática forem as vivências da formação inicial, por exemplo, é no espaço de formação contínua que algumas (re)elaborações serão feitas?

Nesse $3^{\circ}$ encontro, decidimos por trabalhar o conceito de número, sua aquisição pela criança e implicações na prática pedagógica. Não queríamos iniciar a nossa aula e passá-la discutindo os textos apenas. Não que isso não seja importante, deve ser, mas queríamos por no centro do nosso encontro uma atividade com potencial lúdico, como o jogo $\mathrm{Kalah}^{7}$, por exemplo, para problematizar e desencadear discussões acerca da temática. Esperávamos também que a vivência desse jogo pelas estudantes, as aproximasse das vivências lúdicas e lhes permitissem (re)significar as impressões construídas sobre esse tipo de atividade ao longo da vida.

O contato enquanto coordenador-adjunto do PróLetramento matemática, no estado da Bahia, me apresentou o Kalah há alguns anos. Foi como rememorar o trabalho que fazíamos com os formadores do programa e a exploração com o material proposto pelos cadernos de formação. Nesse caso, tendo uma experiência anterior como base, parecia mais tranquilo o transitar pelo espaço do jogo? Não. Agora se tratava de um público diferente e, consequentemente, a exploração do Kalah assumia outra perspectiva. Não só por isso, o momento do jogo sempre nos reserva surpresas. E isso é o mais gostoso de todo esse processo, esperar o que vai ser desencadeado pelo movimento do jogar.

Tendo em vista algumas experiências anteriores em relação à vivência de jogos com crianças, falei sobre a possibilidade de, antes de entregar tabuleiro e peças necessárias para iniciar o jogo, apresentar as regras. Claro que isso vai depender muito do que se objetiva naquele momento. Muitos professores querem que a exploração do jogo seja desencadeadora de hipóteses pela criança; nesse caso, não cabe apresentar as regras antes.

Por quais motivos falei sobre apresentar as regras antes? Algumas estudantes, quando da vivência do jogo Kalah, ficaram eufóricas. Retomar a atenção para apresentar as regras levou um pouquinho de tempo. Construímos o tabuleiro e entregamos os demais materiais antes de apresentar as regras, de propósito, principalmente para destacar que o comportamento de um adulto, no caso, algumas estudantes presentes, se assemelhava ao de crianças. A proposta de jogar, e isso não acontece apenas com crianças, como acabávamos de perceber, gera euforia.

Após construção do tabuleiro, a entrega dos demais materiais necessários para jogar e a explicação das regras, deixamos que, em duplas, jogassem. Circulávamos, a professora e eu, para sanarmos as dúvidas que porventura tivessem e ajudá-las em outras questões referentes ao jogo, além de fazer algumas provocações. Queríamos que elas vivenciassem as diversas situações do jogo, principalmente, porque entendemos que algumas regras, como bem apresenta Brasil (2007), não são compreendidas facilmente. Alguns procedimentos demoram um pouco para se tornarem habituais; por esse motivo, queríamos que jogassem e se apropriassem das questões envolvidas no jogo.

Emily, por exemplo, nos relata em seu diário sobre a dificuldade inicial com o Kalah: "[...] no começo eu e minha colega sentimos dificuldades, logo descobrimos que estávamos burlando algumas regras do jogo, então recomeçamos a jogar e foi muito legal". Entendemos que é necessário um tempo para vivência do jogo e internalização das regras. Sabemos que, como destaca Grando (2008), as primeiras jogadas, muitas vezes, são importantes para essa apropriação, ou seja, são necessárias para garantir que as regras sejam compreendidas e seguidas.

Sinalizei para as estudantes sobre a importância de, para o professor, jogar e conhecer bem as jogadas no movimento do jogo. Não é a mesma coisa conhecer a estrutura, organização do jogo e regras, e conhecer tudo isso dentro do movimento de jogar com alguém. Sugeri que sempre que pensasse em trabalhar com alguma proposta de jogo em suas aulas, fizessem o exercício de jogarem e se apropriarem da atividade.

Lembro-me circular pela sala, após um tempo de jogo, e perceber que havia duas colegas brigando por conta de uma jogada. Interessante como elas "mergulham de cabeça" no universo do jogo. Percebi, ao ler os diários, que um colega, ao lado dessa dupla que brigou, percebeu o ocorrido e registrou: "percebi as colegas ao lado brigando [...] por isso esse jogo

7 Segundo Luvison (2014), a palavra mancala, originada do árabe naqaala, que significa mover, da origem ao nome Kalah. Provavelmente surgido no Egito há cerca de $7 \mathrm{mil}$ anos. Antigamente era associado a ritos mágicos e sagrados e, dependendo do lugar, só era jogado por homens ou pelos mais velhos, sendo, às vezes, exclusivo dos sacerdotes. Segundo Brasil (2007), esse jogo insere-se em um grupo de outros 200 jogos considerados os mais antigos do mundo. 
requer jogo de cintura".

Notamos aqui, que a estudante percebe que existe um comportamento importante para nós, professores, que é saber lidar com as diferentes situações que acontecem em nossas aulas. Muitas vezes, os jogos não são incorporados pelas professoras em sala, justamente pelo "alvoroço" que provoca. É importante que essas situações aconteçam conosco também para entendermos quais são as características, como já destaquei anteriormente, comuns aos jogadores de uma forma geral. Nesse momento, portanto, é importante a nossa intervenção.

Houve registro no diário do tipo: "A experiência dessa forma despertou meu interesse pelas próximas aulas". Parece, e essa é uma impressão minha, que elas não esperavam jogar durante as aulas, dada a surpresa com a proposta. É como se aquele espaço, o da sala de aula da universidade, tivesse um ritual que o caracteriza: textos, teorização, discussão. E por que não fazer tudo isso tendo o jogo como ponto de partida?

Houve estudante que registrou em seu diário: "o lúdico deixa até a matemática mais fácil". A presença do "até" nessa construção revela a possível percepção da matemática como uma disciplina difícil, muitas vezes inacessível, até por meio do jogar. Ainda em relação ao que discutimos anteriormente, Elisa destaca que a aula foi "super bacana". Complementa afirmando que quando tem ludicidade as coisas melhoram. A nossa proposta parecia cumprir o que objetivávamos no início. Elas estavam repensando o papel do jogo no ensino da matemática.

Outro destaque que precisa ser feito é quanto à percepção dessa atividade como algo que pode ser vivenciado em suas práticas futuras. Muitas das estudantes sinalizaram em seus diários, que levarão atividades dessa natureza para as suas aulas. Uma aluna relatou ter construído o Kalah, por exemplo, para jogar com o namorado em sua casa. O jogo, nesse sentido, passa a figurar nas vivências cotidianas das estudantes. Observamos mais claramente aqui, que elas criam um repertório de atividades que consideram importantes para o processo de ensino e aprendizagem da matemática.

A vivência do jogo Kalah fez Hilda retomar em seu diário uma questão que ela nos apresentou ao contar parte de sua história de vida. Segundo ela, o lúdico sempre ficou de fora do ensino de matemática durante os anos finais do Ensino Fundamental. Acredita que isso aconteça não por preguiça ou falta de vontade dos professores, mas sim pela quantidade de conteúdos que são exigidos nesses anos. Ao falar isso, estaria Hilda reconhecendo que o jogo não poderia ser usado para trabalhar os conteúdos e promover aprendizagens nesse sentido? Não sei, mas a impressão que temos aqui, tendo em vista o apresentado, é que a concepção de ludicidade e do uso de jogos em sala de aula por parte dessa aluna é de que eles não contribuem para a construção do conhecimento matemático, afinal, temos que buscar outras maneiras de trabalhar o conteúdo que não seja o jogo.

Perceberam que exageramos na questão anterior? Pois é, o que Hilda nos apresentou não chega a desconsiderar o lugar do jogo no ensino e na aprendizagem da matemática. Sabemos que não, e problematizamos dessa forma só para destacar que algumas pessoas, muitos professores, pensam dessa forma, infelizmente. A vivência desse jogo, ainda segundo Hilda, a fez refletir sobre a sua prática docente e perceber que a presença da ludicidade nas aulas faz bem. Pelo posicionamento apresentado por ela, percebemos o reconhecimento da importância do uso de jogos. O que acreditamos ter sido foco do posicionamento dela é que trabalhar com jogos exige muito mais tempo e cuidado do que com outras ferramentas metodológicas. Nessa lógica quantitativa de muitos conteúdos a se trabalhar, os professores acabam desconsiderando o seu uso.

Para fecharmos a vivência do jogo e propor a ampliação da discussão com as demais leituras da aula, colocamos no quadro algumas situações-problema. Queríamos deixar evidente a necessidade de explorar as diversas situações quando vivenciando o jogo com as crianças. É preciso fazêlas pensar sobre o que experienciaram no jogo, escreverem e refletirem sobre.

Fomos, os estudantes e nós, respondendo conjuntamente as questões das situações-problemas propostas por Luvison (2014). Assim como foi no início do jogo em relação à apropriação das regras do mesmo, algumas estudantes apresentaram dificuldades. Emily registra em seu diário que "depois, com as situações problemas, voltamos a sentir um pouco de dificuldades, mas pensando bastante chegamos às resoluções". Começamos a perceber que houve uma apropriação por parte das estudantes em relação ao jogo e, agora, mais tranquilamente, elas conseguem pensar sistematicamente as jogadas.

Após concluirmos o momento de vivência do jogo, decidimos abrir para discussão, trazendo as leituras dos textos indicados. Queríamos que as estudantes pontuassem, a partir do que foi lido, as questões que consideraram importantes.

Esperávamos que, com tamanho entusiasmo, conseguíssemos envolver as estudantes em relação às duas leituras da semana. Mas seus comportamentos mostravam justamente o contrário. Diferentemente de como foi na aula anterior, dessa vez, as discussões foram mais tímidas e, às vezes, nós a assumimos com mais ênfase. Elas estavam aparentemente acanhadas, pareciam, por um momento, que não haviam feito à leitura dos textos.

Decidimos, portanto, perguntar-lhes pontualmente sobre o conteúdo: conceito e sentido de número. Para nossa surpresa, as estudantes destacam que acharam alguns momentos das leituras complicadas e de difícil compreensão. Elas consideraram alguns pontos da leitura complexos, principalmente o que apresentava a matemática. Nos registros feitos no diário, encontramos: "não gostei da leitura do texto. Muito complexo. Talvez essa estudante esteja despreparada para leituras que envolvam conceitos matemáticos".

Observa-se, no registro narrativo feito no diário, que 
há, por parte da estudante, um reconhecimento de que, para entender o que é proposto no texto em relação ao ensino de matemática, é preciso conhecer alguns conceitos que são próprios da matemática. Elas, portanto, durante a aula, questionaram e apontaram que não entenderam. Após a explicação pela professora, observa-se e ouve-se um: “ah, entendi!".

Nos diários, também, observa-se o registro de que "com a explicação da professora eu entendi”. Só que percebemos que houve uma desestabilização. Elas reconheceram que não sabiam algumas coisas e isso provocou nelas um sentimento de insegurança: "Será que vou dar conta?" "Ensinar matemática é uma tremenda responsabilidade e compromisso", foram algumas falas registradas em seus diários.

É interessante destacar, uma das estudantes lembra e registra um fato que aconteceu em sua infância. Quando da realização de uma atividade, sobre a sequência dos números, a professora organizava a sala e pedia para que cada um, em sua vez, falasse o número que vinha em seguida. Quando era a sua vez, ela respondia baixinho. "Eu falava baixinho a sequência para ela achar que eu sabia”. Era mais ou menos esse comportamento que assumia na aula: ficar quieta para que não percebam que não sei.

Por que algumas estudantes resistem tanto em dizerem e reconhecerem que não sabem? Acredito que essa característica era comum no período em que estudavam na Educação Básica, mas agora, futuras professoras em formação, reconhecer o que não sabe deveria ser algo importante, uma vez que a partir do assumir esse não saber, viria a possibilidade de aprender.

Decidimos, portanto, que apresentaríamos os pontos que consideramos mais importantes do texto e tentaríamos explicar as passagens que as alunas tiveram dificuldade. Para isso, claro, elas iriam precisar apresentar as dúvidas e reconhecer o que não sabiam.

Se observarmos os registros feitos nos diários e na narrativa inicial, por exemplo, veremos que, para muitas estudantes, os anos em que estiveram na Educação Básica enquanto alunas foram marcados pela memorização e mecanização. Infelizmente, como destaca a professora, muito disso tem se mantido. É justamente esse um dos desafios delas, enquanto futuras educadoras matemáticas, além, como destacou Brocardo \& Serrazina (2008), de entender o modo como tem sido encarado o número no currículo.

Levando em consideração o que apresentamos anteriormente, começamos a discutir sobre algoritmos. Uma das estudantes questiona na aula: "Então, o que fizemos no jogo Kalah, por exemplo, de bolar estratégias para vencer e seguir as regras foi a construção de um algoritmo?" Chegamos à conclusão de que sim. Convivemos diariamente com vários tipos de algoritmos que vão desde ligar o computador ou dirigir até seguir uma receita culinária, por exemplo.

Brocardo e Serrazina (2008) apresentam uma pesquisa, realizada por Kamii e Dominick (1998), em que, ao analisar as resoluções de três grupos de alunos, observa-se que o grupo dos não algoritmos apresentou a maior porcentagem de respostas corretas. Observa-se aqui, a importância de dar liberdade aos alunos de inventarem as suas próprias estratégias e procedimentos. Os algoritmos têm sido, mas "[...] não devem ser o foco central do currículo e devem decorrer de um longo trabalho centrado no desenvolvimento do sentido do número" (Brocardo \& Serrazina, 2008, p.106). Chegamos ao fim da aula.

\section{Algumas Considerações}

Para iniciar essa seção de considerações, sinalizamos que a natureza da pesquisa narrativa não nos permite percebê-la como conclusa. A dinamicidade e vivacidade de uma investigação, como a nossa, nos permite entendê-la como inacabada. Sempre, ao olhar para os dados e análises realizadas, as nossas histórias de vida, novas leituras e experiências nos provocarão outras interpretações.

Minha tarefa, enquanto pesquisador narrativo, não foi, quando em contato com os diários e as entrevistas, criar generalizações e dizer que pessoas, lugares e coisas são destas ou daquelas maneiras, mas que elas têm uma história narrativa e que estão avançando. Como já pontuamos em outros momentos desse texto, desejamos, desde o princípio, ampliar o olhar em relação ao puzzle de pesquisa. E foi isso justamente que fizemos. Lembrando que este nosso olhar se aplica para esse grupo em particular e a este momento.

A partir do que objetivamos para este trabalho, teceremos algumas considerações que, para nós, partindo de nossas marcas de vida, nos permite inferir sem generalizar. A pesquisa narrativa, entendendo-a como a melhor forma de compreender a experiência, nos possibilita entender que as experiências em uma sala de aula, como no nosso caso, serão sempre diferentes, uma vez que todos os participantes assim o são. Essas especificidades precisam ser respeitadas. Por isso, a escolha dessa perspectiva de pesquisa foi tão oportuna.

Foi nosso objetivo com a realização desta pesquisa: investigar o que revelam as narrativas de licenciandos do curso de Pedagogia, construídas durante dois encontros da disciplina de "Matemática: conteúdos e seu ensino", sobre a ludicidade, o ensinar matemática no ciclo de alfabetização e o constituir-se professor que ensina matemática nos anos iniciais. Ampliaremos o olhar acerca do objetivado:

O que revelam as narrativas sobre a ludicidade?

O trabalhado realizado com o uso do jogo Kalah, ao longo dos encontros, assume uma dupla funcionalidade: ao tempo que é apresentado como um dispositivo pedagógico que pode ser explorado ao longo de suas futuras práticas, por exemplo, cumpre uma função de trabalhar os conceitos matemáticos e sanar dificuldades que elas mesmas apresentam. Algumas dificuldades conceituais foram manifestas durante o jogo proposto e foi preciso retomar algumas propriedades para trabalhá-las. Durante esse percurso, questões mais teorizadas sobre a ludicidade e a subjetividade que há foram abordadas.

$\mathrm{O}$ que revelam as narrativas sobre o ensinar matemática no 
ciclo de alfabetização?

Tentamos, consoante ao que apresentam os documentos oficiais e curriculares regionais, respeitar os diferentes espaços e formas de matematizar das estudantes para que o perfil de alfabetizadora matemática fosse construído. Nesse movimento de ensinar matemática, algumas questões conceituais que apresentavam dificuldades foram trabalhadas. Ressignificamos alguns pré-conceitos que apresentavam, como "que feio usar os dedos", por exemplo.

O que revelam as narrativas sobre o constituir-se professor que ensina matemática nos anos iniciais?

As estudantes chegaram à disciplina com algumas dificuldades conceituais. Ao longo dos encontros percebemos que as diferentes estratégias formativas propostas contribuíram para repensar essas crenças e ressignificar essas marcas negativas e as dificuldades. Isso nos levou a refletir sobre a importância que tem apresentar diferentes estratégias, as quais as fazem: aprender matemática e significar algumas dificuldades e, também, como possibilidade metodológica para o ensino de matemática futuramente. Esse ressignificar, que falamos anteriormente, permitiu a elas pensarem que, enquanto educadoras matemáticas que atuarão nos anos iniciais, precisam ser diferentes do de muitos professores que elas tiveram. É importante valorizar as diferentes formas de matematizar. Outro ponto importante de reflexão, promovido pelos encontros, foi de que quando futuras professoras, considerem os modos e tempo de aprendizagem de cada criança. Cada uma, diante de problemas matemáticos, apresenta um movimento cognitivo diferente, tendo em vista os conhecimentos que cada uma já possui.

Embora felizes com o trabalho realizado e participação das estudantes, nos restou certa angústia por não ter mais tempo para trabalhar com os conteúdos que elas apresentam mais dificuldades. Espero tê-las envolvido neste processo de formação do professor que ensinará matemática e que continuem a busca por sanar as dúvidas que têm e por se reconhecerem de verdade enquanto educadoras matemáticas, respeitando os espaços de matematizar produzidos pelos estudantes da Educação Básica.

Para os cursos de Pedagogia, no entanto, esperamos que o espaço de formação do professor que ensina(rá) matemática nos anos iniciais seja repensado e que mais atenção seja dada. Infelizmente, por exemplo, ao curso observado, destinasse um número pequeno de horas aulas para a realização do trabalho, além de não ser trabalhado os conceitos de alfabetização matemática antes do início do estágio de alfabetização. Importante um repensar desses cursos e espaços.

\section{Referências}

Almeida, M.B. (2009). A formação inicial de professores no curso de Pedagogia: constatações sobre a formação matemática para a docência nas séries iniciais do Ensino Fundamental. Dissertação (mestrado acadêmico em Educação para a Ciência e a Matemática). Universidade Estadual de Maringá, Maringá
Apple, M. (2005). La entrevista autobiográfica narrativa: Fundamentos teóricos y la praxis del análisis mostrada a partir del estudio de caso sobre el cambio cultural de los Otomíes en México. Forum: Qualitative Social Research, Mexico, maio, 1-35.

Benjamin, W. (1996). Experiência e pobreza. In: W. Benjamin, Magia e técnica, arte e política. Brasília: Brasiliense.

Bondía, J. L. (2002). Notas sobre a experiência e o saber de experiência. Revista Brasileira de Educação, 21-28.

Brasil. (2001). Parecer CNE/CP n ${ }^{\circ}$ 09, de 08 de maio de 2001. Institui as diretrizes curriculares nacionais para a formação de professores da educação básica, em nível superior, curso de licenciatura, de graduação plena. Brasília, DF.

Brasil. (2007). Pro-Letramento. Resolver problemas: o lado lúdico do ensino da matemática. Brasília: MEC, SEB.

Brasil. (2014). Secretaria de Educação Básica. Diretoria de Apoio à Gestão Educacional. Pacto Nacional pela Alfabetização na Idade Certa: Apresentação. Brasília: MEC, SEB.

Brocardo, J. \& Serrazina, L. (2008). O sentido do número no currículo de Matemática: reflexões que intercruzam teoria e prática. In: J. Brocardo, L, Serrazina, \& I, Rocha. O sentido do número: reflexões que entrecruzam teoria e prática (pp. 97-115). Lisboa: Escolar Editora.

Caporale, S.M.M. (2016). Escrever e compartilhar histórias de vida como práticas de (auto) formação de futuros professores e professoras de matemática. 241 p. Tese (Doutorado em Educação). Programa de Pós-Graduação Stricto Sensu em Educação. Universidade São Francisco, Itatiba/SP.

Clandinin, D.J. (2013). Engaging in narrative inquiry. Walnut Creek: Left Coast Press.

Clandinin, D.J., \& Connelly, F. M. (2015). Pesquisa narrativa: experiência e história em pesquisa qualitativa. Uberlândia: EDUFU.

Clandinin, D.J., \& Connelly, F. M. (2000). Narrative inquiry: experience and story in qualitative research. San Francisco: Jossey-Bass.

Cunha, R. B. (2007). Lembranças de escola na formação inicial de professores. In: G.D.V.T, Prado, \& R.B. Cunha, Percursos de autoria: exercícios de pesquisa (pp.97-112). Campinas: Alínea.

Fonseca, M.D.C.F.R. (2014). Alfabetização Matemática. In: Educaciona... Pacto Nacional pela Alfabetização na Idade Certa: Apresentação (pp.27-32). Brasília: MEC.

Grando, R.C. (2008). O jogo e a matemática no contexto da sala de aula. São Paulo: Paulus.

Luvison, C.D.C. (2014). O jogo nas aulas de matemática: leitura, escrita e a resolução de problemas. In: III EEMAI - Encontro de Educação Matemática dos Anos Iniciais. São Carlos: PNAIC. 1-4.

Moretti, V.D. \& Souza, N.M.M.D. (2015). Educação matemática nos anos iniciais do ensino fundamental: princípios e práticas pedagógicas. São Paulo: Cortez.

Moura, M.O.D. (1996). Controle da variação de quantidades: atividades de ensino. São Paulo: FEUSP.

Muniz, C.A. (2016). Educação lúdica da matemática, educação matemática lúdica. In: A.J.N.D.S. Silva, \& H.S. Teixeira, H. S. Ludicidade, Formação de Professores e Educação Matemática em Diálogo. Curitiba: Appris, 17-46.

Nacarato, A. M., Mengali, B. L. S. \& Passos, C. L. B. P. (2009). 
A matemática nos anos iniciais do ensino fundamental. Belo Horizonte: Autêntica.

Pimenta, S G. (1996). Formação de professores - saberes da docência e identidade do professor. In: Revista Faculdade de Educação, 72-89.

Serrazina, L. (1999). Reflexão, conhecimento e práticas letivas em matemática num contexto de reforma curricular no $1^{\circ}$ ciclo. Quadrante, 139-168.

São Carlos. (2012). Projeto Pedagógico do Curso de Licenciatura em Pedagogia. Adequado à Resolução CNE/CP Nº. 01, de 15 de maio de 2006 e Aprovado no Conselho de Graduação, em 12 de dezembro de 2011. São Carlos, 2012.

Silva, A.J.N., Nascimento, A.M. P., \& Muniz, C. A. (2017). O necessário olhar do professor sobre a produção matemática das crianças nos Anos Iniciais. Educação Matemática em Revista, (54), 48-55.

Silva, A.J.N. \& Passos, C.L.B. (2016). Querido diário: o que dizem as narrativas sobre a formação e a futura prática do professor que ensinará Matemática nos Anos Iniciais. Hipátia, $1(1), 46-57$.

Silva, A.J.N.S. (2018). Querido diário... o que revelam as narrativas sobre ludicidade, formação e futura prática do professor que ensina(rá) matemática nos anos iniciais. Tese (Doutorado em Educação) - Universidade Federal de São Carlos, campus São Carlos, São Carlos.

Teles, R.A.D.M. (2014). Direitos e objetivos de aprendizagem e desenvolvimento: a matemática como instrumento de formação e promoção humana. In: Gestão... Pacto Nacional pela Alfabetização na Idade Certa: Apresentação (pp.38-40). Brasília: MEC.

Trujillo, W. (2009). A formação inicial e os conhecimentos do o que e do como ensinar matemática nos anos iniciais do ensino fundamental: encontros e desencontros. Dissertação (Mestrado em Educação) - Universidade Federal de Mato Grosso, Cuiabá/MT. Marta Maria Pontin Darsie. Disponível em: $\quad$ http://D:/Usuarios/Usuario/Downloads/Waldiney_ Trujillo.pdf

Vianna, C.R., Rolkouski, E. (2014). A criança e a matemática escolar. In: Educacional... Pacto Nacional pela Alfabetização na Idade Certa: Apresentação (pp.19-26). Brasília: MEC.

Weller, W. \& Zardo, S. P. (2013). Entrevista narrativa com especialista: aportes metodológicos e exemplificação. Revista da FAEEBA - Educação e Contemporaneidade, 131-143. 